\title{
Bir Vana Gövdesi Parçasında Oluşan Sıcak Yırtılma Hatasının Modellenmesi ve Tasarım Optimizasyonu
}

\author{
Selçuk Şirin ${ }^{1 *}$, Metin Yoldaş² \\ ${ }^{1 *}$ Sakarya Uygulamalı Bilimler Üniversitesi, Hendek Meslek Yüksekokulu, Makine ve Metal Teknolojileri Bölümü, Sakarya, Türkiye, (ORCID: 0000-0002-9129- \\ 9217), selcuksirin@subu.edu.tr \\ ${ }^{2}$ Tunç Metal Döküm San. Tic. Ltd. Şti., Kocaeli, Türkiye, info@tuncmetal.com.tr
}

(Uluslararası Araştırma-Geliştirme ve Tasarım Konferansı - 15-18 Aralık 2021)

(DOI: $10.31590 /$ ejosat.1044780)

ATIF/REFERENCE: Şirin, S. \& Yoldaş, M. (2021). Bir Vana Gövdesi Parçasında Oluşan Sıcak Yırtılma Hatasının Modellenmesi ve Tasarım Optimizasyonu. Avrupa Bilim ve Teknoloji Dergisi, (32), 1029-1033.

Öz

Küresel vanalar, petrol boru hatlarından barajlara kadar çok yaygın kullanım alanına sahip endüstriyel malzemelerdir. Son yıllarda maliyet azaltma ve performans artışı beklentisiyle çeşitli tip ve tasarımlarda vanalar üretilmektedir. Bu durum sonucunda özellikle vana gövdelerinde çok farklı kesit kalınlıkları elde edilmektedir. Döküm yöntemi ile üretilen vana gövdelerinde kesit kalınlıklarındaki bu farklılaşma, bazı alaşım gruplarında sıcak yırtılma riskini ortaya çıkarmaktadır. Bu çalışmada 1.0619 çelik alaşımından dökülen bir vana gövdesi parçasında meydana gelen sıcak yırtılma hatasının kök nedeni araştırılmış ve sonrasında döküm tasarımı optimize edilerek hatasız bir ürün üretilmiştir.

Anahtar Kelimeler: Sicak yırtılma, Döküm simülasyonu, Tasarım Optimizasyonu

\section{Modeling and Design Optimization of Hot Tearing Defect in a Valve Body Part}

\begin{abstract}
Globe valves are industrial materials with a wide range of uses, from oil pipelines to dams. In recent years, valves of various types and designs have been produced with the expectation of cost reduction and performance increase. As a result of this situation, very different section thicknesses are obtained, especially in valve bodies. This variation in cross-section thicknesses of valve bodies produced by casting method reveals the risk of hot tearing in some alloy groups. In this study, the root cause of the hot tear failure occurring in a valve body part cast from 1.0619 steel alloy was investigated and then a defect-free product was produced by optimizing the casting design.
\end{abstract}

Keywords: Hot tearing, Casting simulation, Design Optimisation 


\section{Giriş}

Küresel tip vanalar boru hatlarındaki akışkanların akışını düzenlemek ya da engellemek için kullanılan bir endüstriyel vana türüdür. Vana gövdeleri ise bu sistemlerdeki en kritik bileşenlerdir. Gövdelerin, akışın debisini-basıncını kontrol edebilme, akışı yönlendirme gibi özellikleri kritik öneme sahip olmasındaki ana etkenlerdir. Vana gövdesi iç basıncı taşıyan ana bileşendir ve üretimi genellikle kum döküm yöntemiyle yapılır (Chunlei, Nan, Yuehua, Shuncheng, \& Kaihong, 2019; Galić, Vučković, Tonković, \& Čular, 2020). Kullanım amacına bağlı olarak çok farklı şekillerde ve farklı alaşımlarda gövdeler üretilmektedir. Örneğin basıncın çok yüksek olmadığı yerlerde maliyeti düşürmek amacıyla dökme demir gövdeler kullanılırken, yüksek basınç gereken yerde çelik alaşımları ya da yüksek korozyon direnci istenen yerlerde bronz alaşımları tercih edilmektedir. Son yıllarda çalıșma verimliliğini arttırmak ve maliyetleri miniumuma indirmek amacıyla akışkanlar dinamiği ve sonlu elemanlar yazılımları kullanılarak gövde kesit tasarımlarında çeşitli optimizasyon çalışmaları yapılmaktır (Cho, Yang, Lee, \& Ko, 2007; Lin et al., 2015; Yin, Hu, \& Shu, 2021).

$\mathrm{Bu}$ optimizasyon çalışmaları neticesinde ağırlıklar azaltılmakta ve akış verimlilikleri arttırılmaktadır. Fakat bazı durumlarda bu optimizasyon çalıșmalarının sonucu olarak çok farklı kesit kalınlıklarına sahip olarak üretilen vana gövdelerinde sıcak yırtılma, çatlak, yetersiz besleme gibi döküm hataları meydana gelebilmektedir. Vana gövdelerinin iç kısımlarında akışkanlardan ötürü ciddi basınç oluştuğu düşünüldüğünde hatalı ve kusurlu bir üretimin önemli kayıplara yol açabileceği aşikardır.

Bu gibi hataların önüne geçebilmek için parça optimizasyonu ile birlikte üretim simülasyonlarından da yararlanmak artık günümüzün bir gerekliliğidir. Döküm simülasyon teknikleri, üretim esnasında meydana gelebilecek çekinti, sıcak yırtılma, çatlak oluşumu, yetersiz dolum gibi bir çok döküm hatasını üretim öncesinde bilgisayar başında görmenizi sağlayarak olası işçilik, enerji ve zaman kayıplarının önüne geçebilmenizi sağlar (Colak, Sirin, Kocaman \& Kayıkc1, 2015; Dabade \& Bhedasgaonkar, 2013; Gunasegaram, Farnsworth, \& Nguyen, 2009; Kayikci, Colak, Sirin, Kocaman, \& Akar, 2015).

Sıcak yırtılma, dökümün katılaşma aşamasında meydana gelen bir süreksizliktir. Bulgulara göre, sıcak yırtılmalar, genellikle iki fenomen ile açıklanabilmektedir. Bunlardan birincisi katılaşma sürecinde alaşım elementlerinin sünekten gevrek veya kırılgandan sünek hale dönüşmesi nedeniyle malzeme faz değişimi sıvıdan katıya gerçekleşir, dökümde çatlak başlangıcına yol açar. Bazen katılaşma işlemi sırasında kalıplar ve maça arasındaki farklı daralma nedeniyle sıcak yırtılma meydana gelir. Diğer olgu ise kritik bir sıcaklık aralığında sıvı metalin yetersiz beslenmesi ve dökümün katılaşmış kısmında termal büzülemelerden ötürü bölgesel çekme gerilmelerinin oluşmasıdır (Ol'Khovik, 2016; Pulisheru \& Birru, 2021; Taghiabadi, Fayegh, Pakbin, Nazari, \& Ghoncheh, 2018).
$\mathrm{Bu}$ çalışmada 1.0619 çelik alaşımından dökülen vana gövdesinde karşılaşılan sıcak yırtılma hatası kök neden tespiti için Solidcast programı ile döküm simülasyonu yapılmıştır. Simülasyon sonuçları incelendiğinde yırtılma olan bölgede diğer bölgelere nazaran katılaşma zamanının çok daha uzun olduğu tespit edilmiştir. Müssteri talebi doğrultusunda parça tasarımı üzerinde bir değişiklik yapılamayınca döküm tasarımında bir değişiklik yapılmış ve kabuk tip maça kullanılarak sorun giderilmiştir.

\section{Materyal ve Metot}

\section{1. Üretim}

Tunç Metal firması, müşterisinden gelen talep Şekil 1.de gösterilen küresel vana gövdesi parçasını 1.0619 çelik alaşımından üretim planlamasına başlamıştır. Besleyici-yolluk tasarımı ve model imalatından sonra deneme dökümüne geçilmiştir.

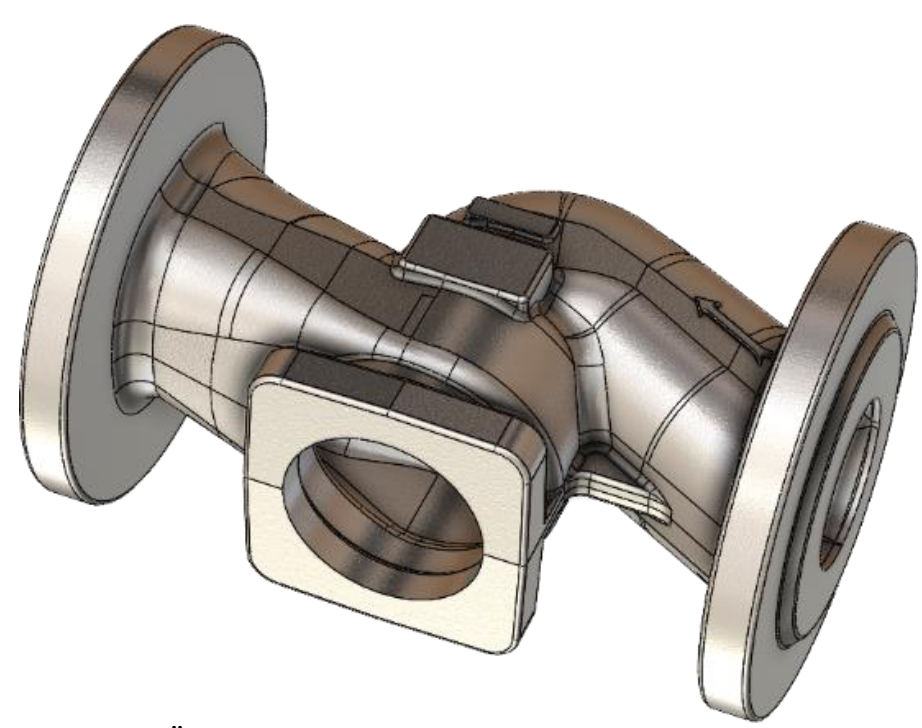

Şekil 1. Üretilecek olan küresel vana gövdesinin CAD datası

1.0619 çelik alaşımı firma tarafından hazırlandıktan sonra döküm öncesinde potadan alınan sıvı metal numune katılaştırılarak Foundry-Master Xpert spektroskopi cihazında analiz edilmiştir. Analiz sonuçları Tablo 1.de paylaşılmışıır.

Tablo 1. 1.0619 alaşımının kimyasal analizi

\begin{tabular}{l|l|l|l|l|l}
\hline $\mathbf{C}$ & $\mathbf{S i}$ & $\mathbf{N i}$ & $\mathbf{C r}$ & $\mathbf{M n}$ & $\mathbf{F e}$ \\
\hline 0,21 & 0,34 & 0,16 & 0,14 & 0,78 & Kalan \\
\hline
\end{tabular}

Deneme dökümler sonrasında parçada belirli bölgelerde sıcak yırtılma hataları görülmüştür. Hataya ait görseller Şekil 2.de paylaşlmıştır. 


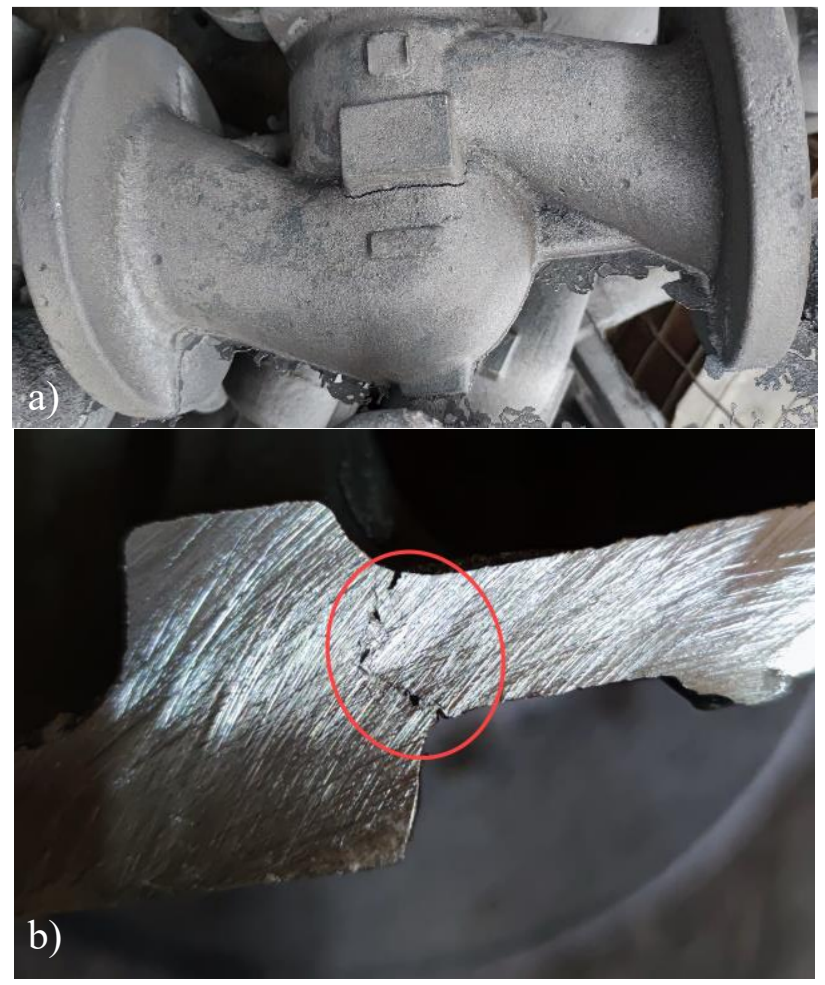

Şekil 2. a) Parçada karşılaşılan sıcak yırtılma hatası, b) Hatanın kesit görüntüsü

Şekil 2. dikkatli bir şekilde incelendiğinde, hatanın nedeninin o bölgedeki ani kesit değişiminden olduğu kanısına varılmış ve parçada ilgili bölge üzerinde tasarım değişikliği talebiyle müşteri firmayla iletişime geçilmiştir. Müşterinin tasarım değişikliğini reddetmesi nedeniyle döküm tasarımında bir değişikliğe gidilmiştir.

\subsection{Sicak Yirtılma}

Sıcak yırtılma, döküm parçalarda karşılaşılan en ciddi kusurlardan biridir. Birçok çalışma bu hata tipinin katılaşmanın son aşamalarında meydana geldiğini ortaya koymuştur. Sicak yırtılmanın oluşumu ve yayılması, soğuma hızı, katılaşma zamanı, sıcaklık gradyanı gibi parametrelerle alaşımın kimyasal bileşimi ve döküm geometrisi gibi nedenlerle doğrudan ilişkilidir (Monroe \& Beckermann, 2005; Stoll, 2009; Wang, Fu, Peng, Wang, \& Ding, 2019).

Sıcak yırtılma, taneler arası kırılma ve pürüzsüz bir kırılma yüzeyi ile karakterize edilen sıcak noktanın olduğu yarı-katı bölgede başlar. Daha önce yapılan çalışmalar, sert kalıp duvarları tarafından engellenen büzülmenin bu kusurun oluşumuna yol açtığını ortaya koymuştur. Büzülme, maşi bölgesi içindeki katılaşma çekintisinden ve maşi bölgesindeki termal büzülmeden oluşur. Katılaşma büzülmesi, katı ve sıvı arasındaki yoğunluk farkından kaynaklanır. Termal büzülme, soğutma sırasında katılaşan parçaların lineer genleşme katsayısı ile ilişkilidir. Yarı katı bölge, son katılaşma aşaması olduğu çok az sünekliğe sahiptir. Çünkü sıvı fraksiyonu, tanelerin çekme gerilimine uyum sağlayarak hareket etmesi için yetersizdir. $\mathrm{Bu}$ nedenle, katılaşmanın son aşamasında tane sınırları boyunca sıcak yırtılma çatlakları meydana gelebilir. Yarı katı bölge ve bu bölgede meydana gelen çekme gerilmesinin şematik görünümü Şekil 3.te verilmiştir.

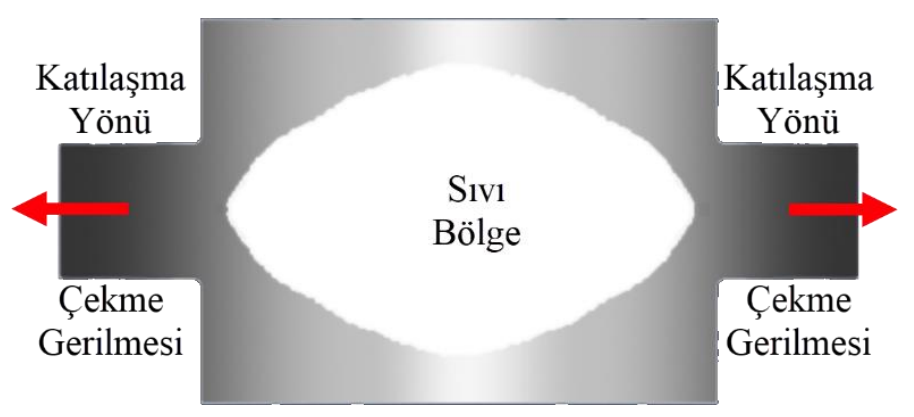

Şekil 3. Sıcak yırtılma mekanizmasının şematik gösterimi

$\mathrm{Bu}$ çalışmada hatalı bölgede kesit kalınlılıklarında farklı olmasından ötürü soğuma hızlarının farklı olduğu düşünülerek döküm tasarımında değişikliğe gidilmiş ve hatalı ürün tasarımında dolu olarak yapılan maça (Şekil 4.a), kabuk maça biçiminde (Şekil 4.c) tasarlanarak simülasyon çalışmasına geçilmiştir.
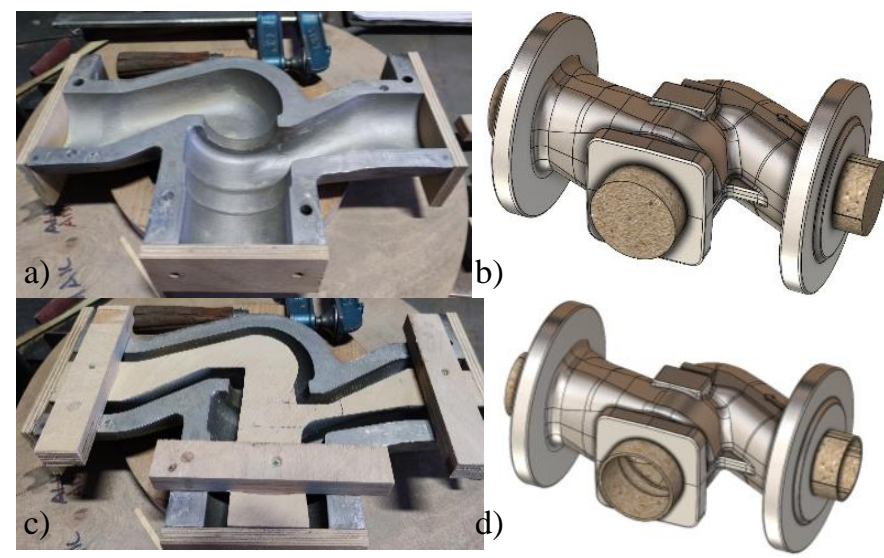

Şekil 4. a) Dolu maça kalıbı, b) Dolu maça kalıp tasarımı, c) Kabuk maça kalıbı, d) Kabuk maça kalıp tasarımı

Simülasyon sonuçları ve yeni tasarıma göre dökülen parçaların görselleri Araştırma Sonuçları ve Tartışma bölümünde paylaşılmıştır.

\section{Araştırma Sonuçları ve Tartışma}

Hatalı üretimden sonra ilk etapta döküm simülasyonu yapılarak ilgili bölgede hatanın nedeni ile ilgili inceleme yapılmış ve sonrasında döküm tasarımında değişkliğe gidilerek vananın iç boşluklarının çıkartılmasını sağlayan maça kısmı dolu halden kabuk tip maçaya çevrilmiştir. Bu tasarım değişikliğinin sebebi hata oluşan bölgede meydana gelen soğuma hızı farklılıklarıdır. Hatalı üretimin döküm simülasyon sonucu Şekil 5.te verilmiştir. Şekil 5.teki simülasyon sonucu Şekil 2.deki dökülen parçanın 
sıcak yırtılan bölge görüntüsüyle eşleştirildiğinde, özellikle yırtılmanın meydana geldiği bölgede hızlı soğuma olduğu, bölgenin sağında ve solunda ise kalın bölgelerden ötürü yavaş soğuma olduğu tespit edilmiştir.

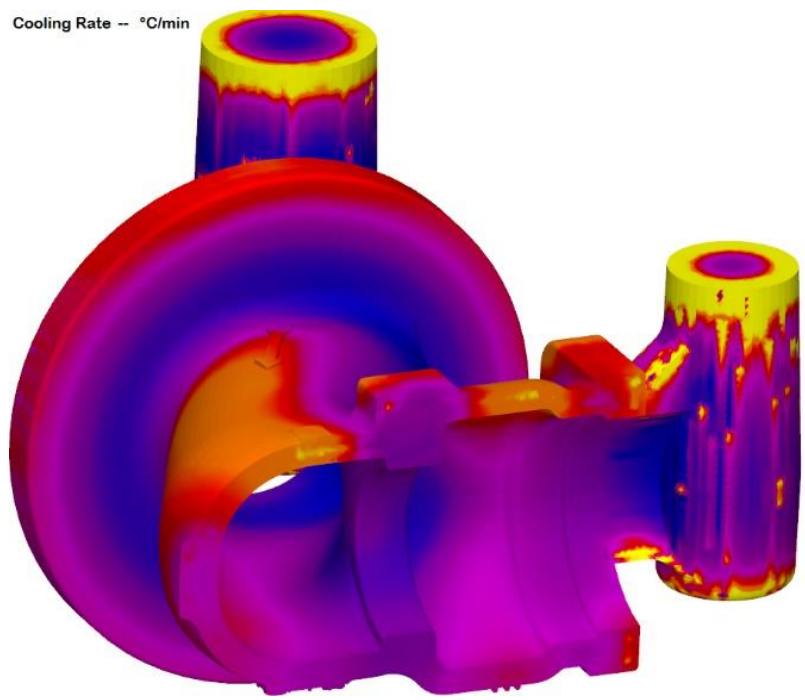

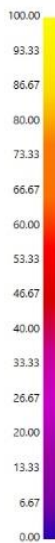

Şekil 5. Hatalı bölgenin soğuma hızı analizi

Hatanın giderilmesi için döküm tasarımında değişikliğe gidilmesine ve dolu maça kütlesinin dökümdeki ince bölgelerin hızlı soğumasına neden olduğu düşünülerek kabuk tip maça tasarımına dönülmesine karar verilmiştir. Kabuk tip maça tasarımlı döküm simülasyonunun soğuma hızı analizi görüntüsü Şekil 6.da verilmiştir.

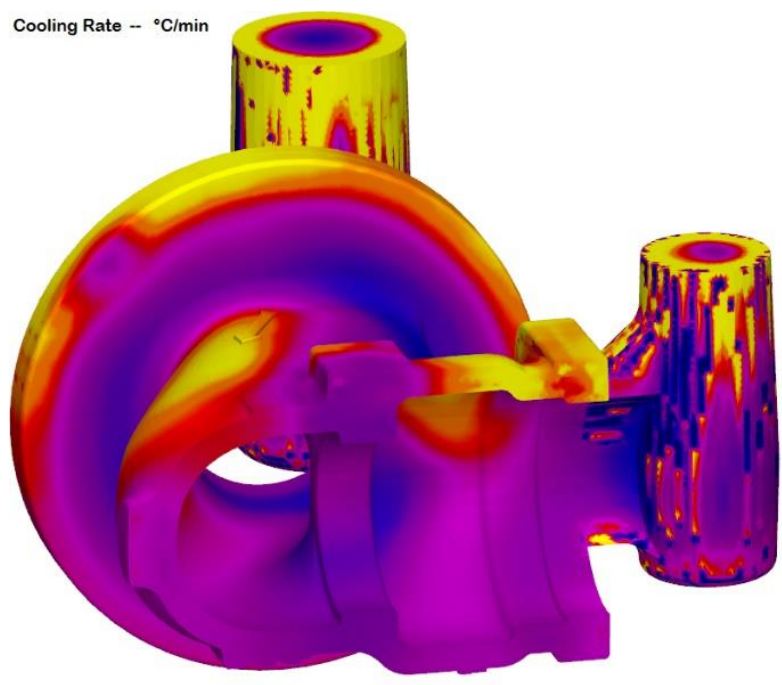

Şekil 6. Kabuk tip maçalı tasarımın soğuma hızı analizi

Kabuk tip maçalı tasarım ile ilk tasarımın (Şekil 5.) simülasyon sonuçları karşılaştırıldığında kabuk tip maçalı tasarımda da nispeten hızlı soğuyan bölgeler olmasına rağmen özellikle hatalı bölgede daha dengeli bir soğuma hızı olduğu görülmüştür. Sonuç olarak kabuk tip maçalı tasarımda karar kılınarak üretime geçilmiştir. Bu tasarıma göre üretilen parçanın gerçek görüntüsü Şekil 7.de paylaşılmıştır. Bu görüntüye göre ilk tasarımda karşılaşılan sıcak yırtılma hatalarına optimize edilmiş kabuk maçalı tasarımda rastlanılmamış ve kabuk maçalı tasarımla seri üretime geçilmiştir.

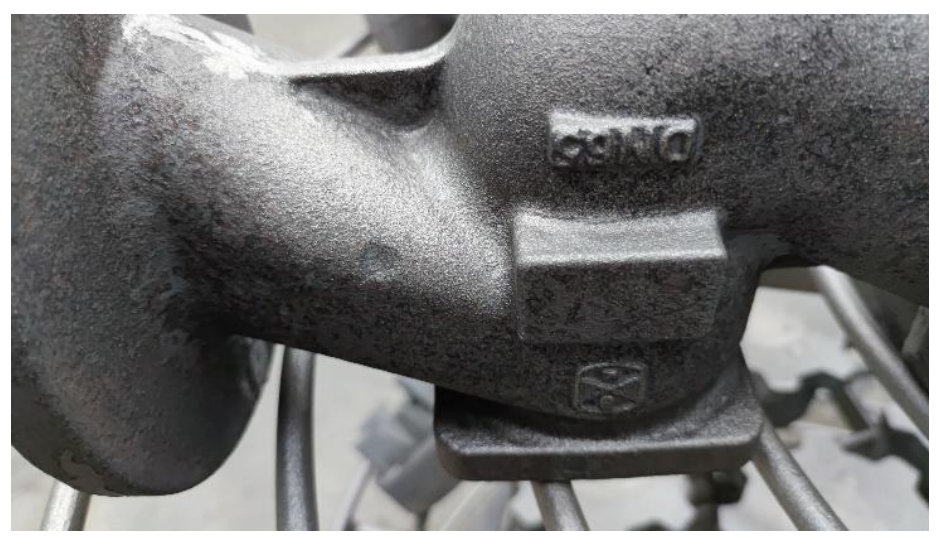

Şekil 7. Kabuk maçalı tasarımla üretilen parçanın gerçek görüntüsü

\section{Sonuç}

$\mathrm{Bu}$ çalışmadan elde edilen sonuçlar aşağıda maddeler halinde sıralanmıştır.

* İlk üretilen parçada hatanın kök nedenine inilerek simülasyon sonuçları incelenmiş ve hatanın soğuma hızı farklılıklarından kaynaklandığı tespit edilmiştir. Bunun sonucunda döküm tasarımında optimizasyon yapılmış ve bu tasarıma göre dökümler gerçekleştirilerek sağlam ürün elde edilmiştir. Simülasyon sonuçları ile gerçek sonuçların örtüştüğü tespit edilmiştir.

* Sicak yırtılma hatasının elimine edilmesinde döküm tasarımı kritik bir öneme sahiptir. Dengeli soğuma ve katılaşma döküm esnasında bu tip hatalarla karşılașılmamasını sağlar. Bu çalışmada da soğuma hızı farklılıkları azaltılarak parçada oluşan sıcak yırtılma hatalarının önüne geçilmiştir.

* Özellikle son dönemlerde verimliliği ve mekanik özellikleri arttımak amacıyla hemen hemen her mühendislik ürününde parça bazlı simülasyon çalışmaları yapılmakta ve teorik olarak ciddi verimlilik artışı sağlanılmaktadır. Fakat üretilebilirlik konusu irdelenemeden yapılan her optimizasyon karşımıza kayıp olarak çıkabilir. Dolayısıyla ürün bazlı optimizasyon çalışmalarında üretim ayağı da düşünülerek döküm simülasyonu gibi üretim simülasyonu yazılımlarından faydalanılmalıdır.

\section{Kaynakça}

Cho, T. D., Yang, S. M., Lee, H. Y., \& Ko, S. H. (2007). A study on the force balance of an unbalanced globe valve. Journal of Mechanical Science and Technology, 21(5), 814-820. https://doi.org/10.1007/BF02916360

Chunlei, G., Nan, Z., Yuehua, K., Shuncheng, W., \& Kaihong, Z. (2019). Failure analysis of lead-free brass valve bodies. Engineering Failure Analysis, 100(March), 536-543. https://doi.org/10.1016/j.engfailanal.2019.03.001

Colak, M., Sirin, S., Kocaman, E., KayIkcI, R., \& Kayıkс1, R. (2015). Investigation and modelling of the effects of solidification time and grain refinement on the grain size of a sand-cast $\mathrm{A} 14 \mathrm{Cu}$ alloy. AIP Conference Proceedings, 1653(April 2015), 1-6. https://doi.org/10.1063/1.4914221

Dabade, U. A., \& Bhedasgaonkar, R. C. (2013). Casting defect 
analysis using design of experiments (DoE) and computer aided casting simulation technique. Procedia CIRP, 7, 616621. https://doi.org/10.1016/j.procir.2013.06.042

Galić, I., Vučković, K., Tonković, Z., \& Čular, I. (2020). Numerical simulation of initiation and crack growth on cast valve body. Engineering Failure Analysis, 117(July). https://doi.org/10.1016/j.engfailanal.2020.104793

Gunasegaram, D. R., Farnsworth, D. J., \& Nguyen, T. T. (2009). Identification of critical factors affecting shrinkage porosity in permanent mold casting using numerical simulations based on design of experiments. Journal of Materials Processing Technology, 209(3), 1209-1219. https://doi.org/10.1016/j.jmatprotec.2008.03.044

Kayikci, R., Colak, M., Sirin, S., Kocaman, E., \& Akar, N. (2015). Determination of the critical fraction of solid during the solidification of a PM-cast aluminium alloy. Materiali in Tehnologije, $\quad 49(5), \quad 797-800$. https://doi.org/10.17222/mit.2014.266

Lin, Z., Wang, H., Shang, Z., Cui, B., Zhu, C., \& Zhu, Z. (2015). Effect of cone angle on the hydraulic characteristics of globe control valve. Chinese Journal of Mechanical Engineering (English Edition), 28(3), 641-648. https://doi.org/10.3901/CJME.2015.0313.030

Monroe, C., \& Beckermann, C. (2005). Development of a hot tear indicator for steel castings. Materials Science and Engineering $\quad A, \quad 413-414($ July), 30-36. https://doi.org/10.1016/j.msea.2005.09.047

Ol'Khovik, E. (2016). Development the Methods for Preventing Hot Cracking with Use Analysis of Temperature Fields. IOP Conference Series: Materials Science and Engineering, 142(1). https://doi.org/10.1088/1757-899X/142/1/012084

Pulisheru, K. S., \& Birru, A. K. (2021). Effect of pouring temperature on hot tearing susceptibility of Al-Cu cast Alloy: Casting simulation. Materials Today: Proceedings, 47, 70867090. https://doi.org/10.1016/j.matpr.2021.06.182

Stoll, H. W. (2009). Casting Design and Performance. In ASM International, $p 49$.

Taghiabadi, R., Fayegh, A., Pakbin, A., Nazari, M., \& Ghoncheh, M. H. (2018). Quality index and hot tearing susceptibility of $\mathrm{Al}-7 \mathrm{Si}-0.35 \mathrm{Mg}-\mathrm{xCu}$ alloys. Transactions of Nonferrous Metals Society of China (English Edition), Vol. 28, pp. 12751286. https://doi.org/10.1016/S1003-6326(18)64783-1

Wang, K., Fu, P., Peng, L., Wang, Y., \& Ding, W. (2019). A Simplified Hot-Tearing Criterion for Shape Castings Based on Temperature-Field Simulation. Metallurgical and Materials Transactions A: Physical Metallurgy and Materials Science, 50(11), 5271-5280. https://doi.org/10.1007/s11661019-05408-5

Yin, J., Hu, R., \& Shu, X. (2021). Closed-die forging process of copper alloy valve body: Finite element simulation and experiments. Journal of Materials Research and Technology, 10, 1339-1347. https://doi.org/10.1016/j.jmrt.2020.12.087 